\title{
RELIABILITY MEASURE OF A SEWER NETWORK
}

\author{
Ermolin Y. A., Alexeev M. I.
}

\section{МЕРА НАДЕЖНОСТИ КАНАЛИЗАЦИОННОЙ СЕТИ}

\author{
Ермолин Ю. А., Алексеев М. И.
}

\begin{abstract}
Introduction: the ramified sewerage system for receiving and transferring household and industrial sewage typical for a large city is considered. Consideration is restricted to the sub-system of sewage conveyance (sewer network). Methods and materials: the relative raw sewage volume that could be potentially discharged to the environment as a result of component failures in the sewer network is proposed as a measure of overall system reliability. Results: a simple method for quick and proper calculation of this volume is presented. The problem reduced to finding of the raw sewage volume potentially discharged from the sewer network, and is solved using the following assumptions and limitations: mathematically, an urban sewer network is a simply connected, acyclic, oriented graph (so-called tree-like graph); of a pipe fails, its capacity becomes equal to zero; all specific peculiarities of a pipe (material, diameter, age, operating conditions, etc.) manifest itself in its failure rate; the network pumping stations are taken absolutely reliable. The basis for this method is a representation of the sewer network by a combination of structure-forming fragments. Each such fragment is formally substituted by a fictitious equivalent sewer that has a failure rate leading to the same output for the same input. Conclusion: as a result, the problem reduces to a sequential consideration of elementary sub-problems the solution of which is easily accomplished.
\end{abstract}

Keywords: sewer network, reliability, sewage discharge, Y-like network fragment, decomposition-equivalenting method.

\section{Introduction}

The proper functioning of the urban sewage disposal system is a primary determinant of the city's ecological and sanitary-hygienic conditions. Confronting problems associated with the sewer network maintenance as a subsystem of an entire sewage disposal system, is a necessary step for improving operation efficiency in an urban waste

\begin{abstract}
Аннотация
Введение: рассматривается типичная для крупного города разветвленная канализационная система, предназначенная для приема и отведения бытовых и промышленных сточных вод. Рассмотрение ограничивается подсистемой транспортировки воды (канализационной сетью). Методы и материалы: предлагается под мерой надежности системы в целом понимать относительный объем неочищенной сточной воды, потенциально сбрасываемой в окружающую среду вследствие случайного выхода из строя компонентов канализационной сети. Результаты: разработан простой метод быстрого и точного расчета этого объема. Задача сводится к определению количества неочищенной воды, потенциально сбрасываемой из сети, и решается при следующих допущениях и ограничениях: городская система водоотведения, с математической точки зрения, представляется односвязным, ациклическим, ориентированным графом (так называемым «деревом»); при аварии трубы ее пропускная способность считается равной нулю; специфические особенности каждой трубы (материал, диаметр, возраст, условия работы и т. п.) интегрально проявляются в интенсивности ее отказов; канализационные насосные станции сети полагаются абсолютно надежными. В основе метода лежит представление канализационной сети в виде комбинации структурообразующих фрагментов. Каждый такой фрагмент формально заменяется одной фиктивной эквивалентной трубой, интенсивность отказов которой определяется из условия равенства расходов воды на входах и выходе фрагмента и заменяющей его трубы. Заключение: расчет меры надежности канализационной сети сводится к последовательному рассмотрению простых подзадач, решение каждой из которых элементарно и не вызывает трудностей.

Ключевые слова: канализационная сеть, надежность, сброс сточной воды, Ү-образный фрагмент сети, метод декомпозиции и эквивалентирования.
\end{abstract}

water disposal system as a whole. In recent years, in response to increasing congestion in urban sewer networks and the adverse environmental impact of such congestion, substantial attention has been focused on working out the proposals to improve waste water disposal processes. A critical issue in the evaluation and effective implementation of these proposals is development 
of the best, in some specified sense, sewage disposal strategies. In practice, meanwhile, very significant improvements in management efficiency could be accomplished simply by better maintenance of the waste water disposal system.

There is a great deal of research dedicated to the reliability problems of water supply systems reported in the literature $[2-4,7,13-15,17]$. From the latest publications we emphasize the work of Gheisi et. al. [8], which provides an in-depth review of the relevant research literature in the context of the mathematical methods for measuring water distribution system reliability. However, as noted in other works, for example: "A review of the literature reveals that there is currently no universally acceptable definition or measure of the reliability of water distribution systems ... For a large system ... it is extremely difficult to analytically compute the mathematical reliability" [13].

By contrast, the reliability problems of the sewage disposal systems are still uninvestigated $[5,6,9,10$, $12,18]$. Therefore, any effort to comprehend, set up and refine the issue of sewer network reliability takes on great significance. The final objective of these investigations is to develop sewer network design, reconstruction and maintenance methods with due regard for reliability.

\section{Short description of the object and problem statement}

An urban wastewater disposal system is a network of structurally and technologically interconnected structures intended for sewage collection and its conveyance to the purification plants. Usually the city sewage disposal system is designed and constructed according to the head-andgravity concept. This means that the sewage passes through underground sewers having a specified fall by gravity, and pumping stations lift sewage in areas where gravity flow is impossible. (As a rule, the sewage pumping station is designed as a system providing a redundancy of the pumping equipment. Because of this, in the following, we assume that the pumping stations are absolutely reliable).

By this means the sewer network, by nature, is a peculiar water distribution system. The reliability of such systems is often defined by heuristic guidelines, like having all pipe diameters greater than a minimum prescribed value. By using such guidelines it is implicitly assumed that reliability will be assured, but the level of reliability provided is not quantified or measured. Thus, the question: "Is the system reliable?" is usually well understood and easy to answer, while the question "What is its reliability level?" is not straightforward. As a result, only limited confidence can be placed on such rules, as reliability is not considered explicitly.

The underground pipes, as sewer network components, are subject to so many influences that it is difficult, if not impossible to predict their combined effect in advance. These influences include the corrosive action of the soil and sewage, ground movements, etc. Most of these factors are random, and are characterized by significant variability. These circumstances adversely affect sewer network reliability. Currently, traditional wastewater disposal system design and maintenance methods usually fail to account for this situation.

A determination of the timeline and the sequence of a sewerage modernization plan is an important problem of the applied reliability theory. The strategy development for the object reconstruction falls into two stages. At the first stage, the object's technical condition is established, and a need for renovation is determined. The second stage is job scheduling for the specific network elements requiring repair or replacements.

Depending on the purpose of the study and the specifics of an object, its technical state may be estimated, from the viewpoint of a reliability, using different quantitative measures: for example, by the average time between failures or by the probability of trouble-free functioning over a given period of time. We note that these traditional measures, accepted in theory, as applied to sewer networks, provide not enough information because it is very hard to interpret them physically.

Here the specific reliability index is proposed. This index is intended for functioning efficiency estimation of tree-like hierarchical structures; an urban sewer network is a typical representative of such structure. The relative volume of raw sewage potentially discharged from the sewer network to the environment over some time period (for example, one year) resulting from network components failures, is considered as a quantitative reliability measure. 
Thus, the problem reduced to finding of the raw sewage volume potentially discharged from the sewer network.

\section{Assumptions and limitations}

The following basic assumptions and limitations are accepted in the subsequent consideration:

- Mathematically, an urban sewer network is a simply connected, acyclic, oriented graph (socalled tree-like graph).

- If a pipe fails, its capacity becomes equal to zero.

- All specific peculiarities of a pipe (material, diameter, age, operating conditions, etc.) manifest itself in its failure rate.

- The network pumping stations are taken absolutely reliable.

\section{Reliability analysis of the sewer network fragment}

Two features of a sewer network should be pointed out: 1) sewage gravitates through each sewer in one direction only, and 2) the hydraulic elements used to link different sewer basins are lacking. This means particularly that the sewage entering into any network inlet, may be piped to a certain its outlet by a strictly specified sequence of sewers, i.e. along the only path.

We consider the three-component Y-like sewer network fragment shown in Fig. 1.

Each enumerated sewer of this fragment is characterized by its length $\left(L_{1} ; L_{2} ; L_{3}\right)$; in addition, we suppose that the unidirectional sewage flow rates in the inlets of sewer 1 and 2 ( $q_{1}$ and $q_{2}$, respectively) are known, constant and equal to the mean values calculated by averaging the historical data obtained over a long period of time. We assume that, from time to time, each sewer fails, is repaired and, thereafter, put back in service again. Thus, each sewer can be either up (operable) or down (failed). This means that so-called failure and repair flows are both acting on each sewer.

For a mathematical description of these flows, what is meant by term "failure" must be ascertained.

The exact definition of failure is somewhat vague and depends on the level of detail of the required analysis, and has a variety of meanings to different individuals. In actual practice, a disturbance of the normal operation of the sewer can be manifested as a reduction of its capacity caused by cracks in the pipe, sewer breaks under extreme mechanical load, increasing rates of infiltration, repeated overflows, etc. Here, we shall define "failure" as an event implying a need for immediate overhaul or replacement of the pipe. In other words, the failure of a sewer is defined as an event when the sewer capacity becomes equal to zero, and consequently, all sewage entering into the sewer discharges to the environment.

The repair is taken here to mean that a renewal process reaches completion and the sewer is returned to service.

Usually, such events are documented with accompanying parameters. This information is systematically renewed, statistically processed and stored in relevant data bases.

Both of these flows are characterized by their rates. Physically, the failure rate is the mean number of failures in a unit of time. The repair rate is defined similarly. In line with a much used assumption, we suppose that the failure flow as well as the repair flow are exponentially distributed flows [11, 13]. From this it follows that the specific failure rate (the failure rate per unit sewer length) for each sewer $\left(\left(\lambda_{0}\right)_{1},\left(\lambda_{0}\right)_{2},\left(\lambda_{0}\right)_{3}\right.$, respectively) is constant. Analogously, the repair rates for sewers 1,2 and 3 $\left(\mu_{1}, \mu_{2}, \mu_{3}\right)$ are constant as well. We assume that all these values are given.

The problem is stated as follows: given the values of all quantities listed above, it is necessary to estimate the volume of raw sewage discharged from the sewer network to the environment over some time period (one year in this study).

This problem formulated for the sewer network, shown in Fig. 1, is solved in [5] using so-called

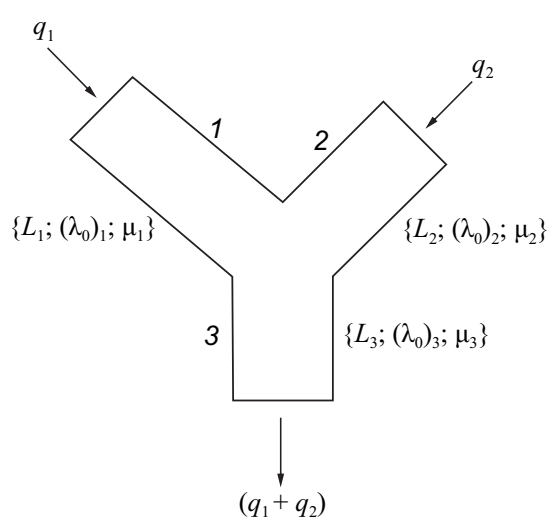

Fig. 1. Y-like sewer network fragment 
state-enumeration method [16]. The Y-like sewer system shown in Fig. 2, $a$ is superseded formally with an equivalent fictitious sewer 123 , having the dimensionless parameter $\gamma_{e}=\gamma_{123}$ and sewage flow rate at the inlet $\left(q_{1}+q_{2}\right)$ (Fig. 2,b)).

The parameter $\gamma_{e}$ is calculated by formula:

$$
\gamma_{e} \approx \frac{\left(\gamma_{1}+\gamma_{3}\right) q_{1}+\left(\gamma_{2}+\gamma_{3}\right) q_{2}}{q_{1}+q_{2}}
$$

where $\gamma_{1}=\lambda_{1} / \mu_{1} ; \gamma_{2}=\lambda_{2} / \mu_{2} ; \gamma_{3}=\lambda_{3} / \mu_{3}$; and, in its turn, $\lambda_{1}=\left(\lambda_{0}\right)_{1} L_{1} ; \lambda_{2}=\left(\lambda_{0}\right)_{2} L_{2} ; \lambda_{3}=\left(\lambda_{0}\right)_{3} L_{3}$.

Sometimes, the cases occur when at one point of network more than two (generally, $k$ ) sewers are connected (Fig. 3,a))

In this case, as shown in [1], $\gamma_{e}$ must be calculated by formula:

$$
\gamma_{e}=\gamma_{k+1}+\frac{\sum_{i=1}^{k} \gamma_{i} q_{i}}{\sum_{i=1}^{k} q_{i}}
$$

and, then, the system depicted in Fig. 3, $a$ can be superseded by one sewer as shown in Fig. 3, $b$.

As is shown in [5], the numerical value of $\gamma_{e}$ is a part of $Q$ that is not conveyed to the network

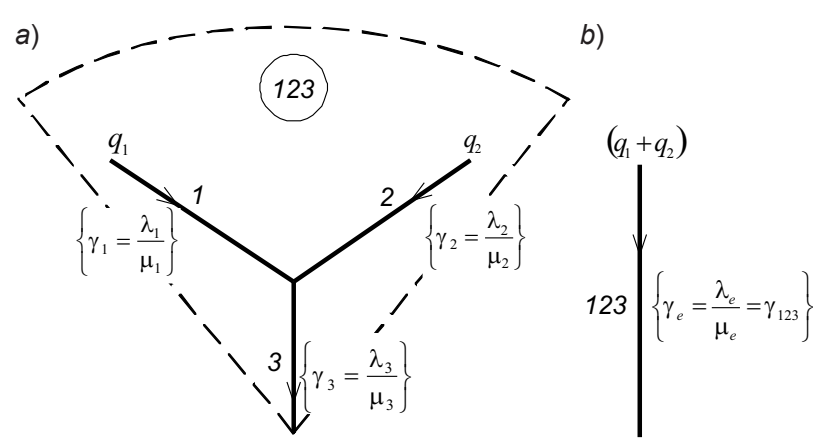

Fig. 2. Three-component network (a) and its equivalent (b) a)

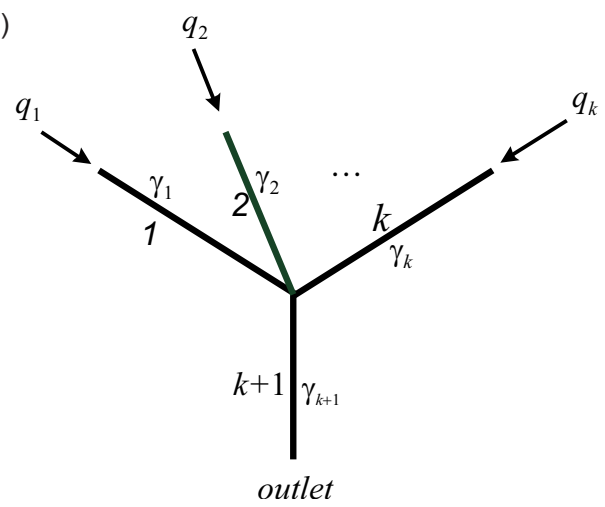

b)

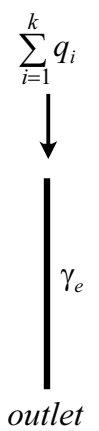

Fig. 3. Extension of the equivalenting procedure outlet, i.e. is discharged to the environment. When multiplied by $100, \gamma_{e}$ physically shows the raw sewage discharge resulting from sewer network failures, expressed as a percentage of total sewage volume entered to its inlets. By virtue of the fact that $\gamma_{e}$ is varied from 0 (absolutely reliable network) to 1 (theoretically, completely inoperable network), the parameter $\gamma_{e}$ may be used as an objective, singlevalued measure of the sewer network reliability.

We emphasize that the sewer network fragment of Fig. 2, a) (or Fig. 3,a)) is a structure-forming component in the sense that any arbitrary complicated dendritic sewer network may be thought of a composition of such components. Below we give a technique of how to apply this approach.

\section{Decomposition-equivalenting technique}

We shall call this procedure as the "decompositionequivalenting technique". It is more convenient to demonstrate this technique by the following example.

Consider the network in Fig. 4, $a$ consisting of seven sewers, each determined by the values $\lambda_{i}$ and $\mu_{i}$, and, hence, by the value $\gamma_{i}=\lambda_{i} / \mu_{i}(i=1 \div 7)$. In addition, the sewage flow rate at the network inlets $\left(q_{1}, q_{2}, q_{3}, q_{4}\right)$ will be considered to have constant values. It is necessary to estimate the raw sewage volume discharged from the network throughout the year as a consequence of possible failures.

First we consider the contours I and II in Fig. 4, $a$. Either contour includes the Y-like system, and, consequently, can be substituted by one equivalent sewer with its associated value of parameter $\gamma$ calculated according to the method proposed above. Using Eq. (1), we have $\gamma_{I}$ for contour I. Similarly, with assigned notations, for contour II we have $\gamma_{I I}$.

The results obtained enable one to present the initial network in the form shown in Fig. 4, b). But this is an Y-like system (contour III) again. Using Eq. (1), we have finally the parameter $\gamma_{I I I}=\gamma_{e}$ of one equivalent sewer substituting the initial network (see Fig. $4, c$ ). Thus, the problem reduces to a sequence of simple computations using, at every stage, the results of the preceding step.

Although this methodology has been applied to a comparatively simple case, it can be extended easily to multicomponent networks.

(The application of the "decompositionequivalenting technique" for more complicated 


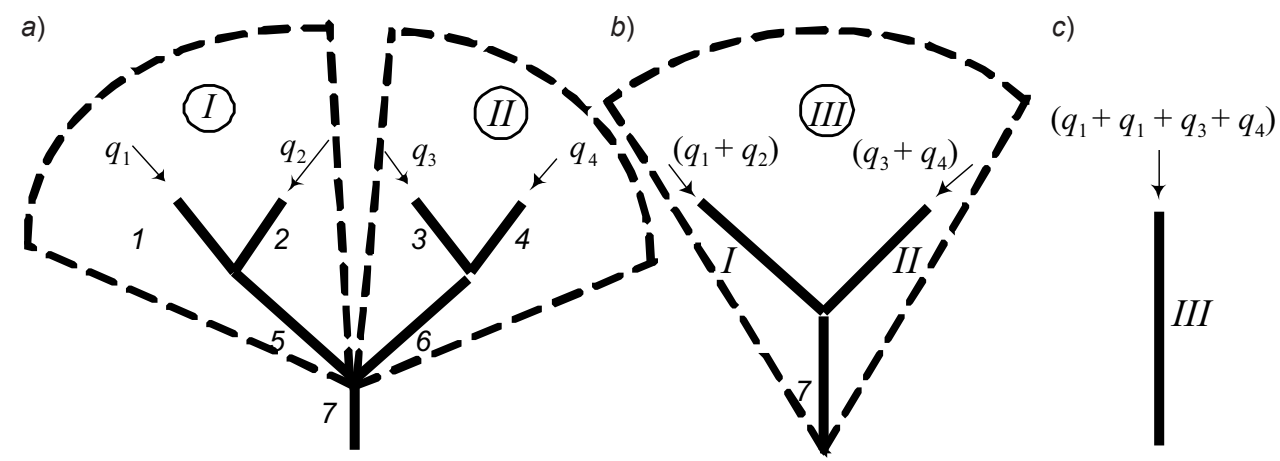

Fig. 4. Decomposition-equivalenting technique

sewer network is considered in "Supplemental material'").

\section{Conclusion}

Although sewer reliability depicts a fairly complete reliability measure of the sewer network, it is convenient to use a single index to represent the composite effect of the component reliabilities. We propose to assess sewer network reliability as a whole by a volume of raw sewage discharged from the system because of failures of its components for an appreciable length of time. The traditional method for solving such problems is the so-called stateenumeration method. But, for the multicomponent networks, this generates a need to solve a set of equations having very high order, which renders the method unsuitable for many practical applications. The approach proposed in this work makes it possible to circumvent these difficulties by using the concept of equivalent sewer. As a result, the problem reduces to a sequential consideration of elementary sub-problems the solution of which is easily accomplished (see "Supplemental material").

As the methodology is applicable for sewer networks each component of which can be either up (operable) or down (failed), additional research is needed for extending the method for more complex cases.

\section{References}

1. Alekseev, M. I., Ermolin, Yu. A. (2010). Extension of the decomposition-equivalenting technique at the estimating of sewer network reliability. In: Proc. of the Conference in memory of academician S. V. Iakovlev, St. Peterburg: St. Peterburg State University of Architecture and Civil Engineering, pp. 19-21. (in Russian).

2. Bao, Y., Mays, L. W. (1990). Model for water distribution system reliability. J. of Hydraulic Engineering, vol. 116, pp. 1119-1137.
3. Yen, B. C., Tung, Y.-K. (ed.) (1993). Reliability and Uncertainty Analyses in Hydraulic Design. New York: American Society of Civil Engineers, 305 p.

4. Engelhardt, M. O., Skipworth, P. J., Savic, D. A., Saul, O. A. (2000). Rehabilitation strategies for water distribution networks: a literature review with a UK perspective. Urban Water, vol. 2, pp. 153-170.

5. Ermolin, Y. A. (2001). Estimation of raw sewage discharge resulting from sewer network failures. Urban Water, vol. 4, pp. 271-276.

6. Ermolin, Y. A. (2009). Reliability Estimation of Urban Wastewater Disposal Networks. In: Reliability Engineering Advances, New York: Nova Science Publishers, pp. 379-397.

7. Fujiwara, O., Ganesharajah, T. (1993). Reliability assessment of water supply systems with storage and distribution networks. Water Resources Research, vol. 29, pp. 2917-2924.

8. Gheisi, A., Forsyth, M., Naser, Gh. (2016). Water Distribution Systems Reliability: A Review of Research Literature. J. of Water Resources Planning and Management, vol. 142, issue 11, pp. 83-94.

9. Haghighi, A., Bakhshipour, A. E. (2016). Reliabilitybased layout design of sewage collection systems in flat areas. Urban Water Journal, vol. 13, issue 8, pp. 780-802.

10. Jin, Y., Mukherjee, A. (2010). Modeling blockage failures in sewer systems to support maintenance decision making. J. of Performance of Constructed Facilities, vol. 6, pp. 622-633.

11. Korn, G., Korn, T. (1961). Mathematical Handbook for Scientists and Engineers. New York, Toronto, London: McGraw-Hill Company, Inc., 943 p.

12. Kwietniewski, M., Lesniewski, M. (2006). The reliability assessment of a typical structure fragment of a stormwater collection network including uncertainty. In: Photonics Applications in Astronomy, Communications, Industry, and High-Energy Physics Experiments IV, Wilga.

13. Mays, L. M. (ed.) (1989). Reliability analysis of water distribution systems. New York: American Society of Civil Engineering, $544 \mathrm{p}$.

14. Quimpo, R. G., Shamsi, U. M. (1991). Reliability based distribution system maintenance. J. of Water Resources Planning and Management Division, vol. 117, pp. 321-339.

15. Su, Y. C., Mays, L. W., Duan, N., Lansey, K. E. (1987). Reliability-based optimization model for water distribution systems. J. of Hydraulic Engineering, vol. 114, pp. 1539-1556. 
16. Ventzel, E. (2001). Issledovanie operacij: zadachi, principy, metodologiya [Operations Analysis: Problems, Principles and Methodology]. M.: Vysshaja Shkola, 318 p. (in Russian).

17. Wagner, J. M., Shamir, U., Marks, D. H. (1988). Water distribution reliability. Analytical methods. J. of Water Resources Planning and Management Division, vol. 114, pp. 253-275.

18. Yermolin, Yu. A., Alexeev, M. I. (2012). Nadezhnost' vodootvodyashchih setej i puti ee povysheniya [Reliable operation of wastewater collection systems and ways of its improvement]. Water Supply and Sanitary Technique, vol. 1. pp. 13-16. (in Russian).

\footnotetext{
Авторы

Ермолин Юрий Александрович, д-р техн. наук, профeccop

Российский университет транспорта (МИИТ)

E-mail: ermolin.y@yandex.ru
}

Алексеев Михаил Иванович, д-р техн. наук, професcop

Санкт-Петербургский государственный архитектурностроительный университет

E-mail: m.i.alexeev@mail.ru

\section{Authors}

Ermolin Yuri Aleksandrovich, Doctor of Engineering, Professor

Russian Transport University (MIIT)

E-mail: ermolin.y@yandex.ru

Alekseev Mihail Ivanovich, Doctor of Engineering, Professor

St. Peterburg State University of Architecture and Civil Engineering

E-mail:m.i.alexeev@mail.ru

\section{Supplemental material}

The method developed in this article may be used to solve many practical problems. Some of these, in the form of numerical examples, are considered below in a deliberately simplified statement.

Problem 1. The sewer network shown in Fig. S1, $a$ is given. There is a need to estimate a reliability level of this network (in the sense of the proposed criterion).

The network consists of 15 enumerated sewer sections; the number of inlets is equal to 8 . The direction of the sewage flow through an each sewer is shown by the arrow. To carry out the calculations we need some data. Such data are represented in Table 1

Besides, the inlets sewage flow rates in Table 2 are shown.
In addition, without loss of generality, we assume that the length of each sewer section is equal to 1 $\mathrm{km}$. We note also that all values are hypothetical, convenient for calculations only.

First we consider the contours I, II and III (Fig. S1a) at the network periphery. Either contour includes the Y-like system, and, consequently, can be substituted by one equivalent sewer with its associated value of parameter $\gamma$ calculated according to the method proposed above. Using Eq. (1) (from the article), where now, taking account of the new notations, and the data from Table 1 and Table 2 we have for contour $I$ :

$$
\gamma_{I}=\frac{\left(\gamma_{2}+\gamma_{9}\right) q_{2}+\left(\gamma_{3}+\gamma_{9}\right) q_{3}}{q_{2}+q_{3}}=7,54 \cdot 10^{-3}
$$

Similarly, for contour II:

$$
\gamma_{I I}=\frac{\left(\gamma_{5}+\gamma_{13}\right) q_{5}+\left(\gamma_{6}+\gamma_{13}\right) q_{6}}{q_{5}+q_{6}}=5,85 \cdot 10^{-3},
$$

and for contour $I I I$ :

$$
\gamma_{I I I}=\frac{\left(\gamma_{7}+\gamma_{14}\right) q_{7}+\left(\gamma_{8}+\gamma_{14}\right) q_{8}}{q_{7}+q_{8}}=4,00 \cdot 10^{-3} .
$$

The results obtained enable one to present the initial network in the form shown in Fig. S1, b). But here are the Y-like systems (contours $I V$ and $V$ ) again. Using Eq. (1) we have the parameter $\gamma_{I V}$ for contour $I V$ :

$$
\gamma_{I V}=\frac{\left(\gamma_{1}+\gamma_{10}\right)\left(q_{2}+q_{3}\right)+\left(\gamma_{4}+\gamma_{10}\right) q_{4}}{q_{2}+q_{3}+q_{4}}=10,95 \cdot 10^{-3}
$$

and $\gamma_{V}$ for contour $V$ :

$$
\begin{gathered}
\gamma_{V}= \\
\frac{\left(\gamma_{I I}+\gamma_{12}\right)\left(q_{5}+q_{6}\right)+\left(\gamma_{I I I}+\gamma_{12}\right)\left(q_{7}+q_{8}\right)}{q_{5}+q_{6}+q_{7}+q_{8}}= \\
=13,79 \cdot 10^{-3} .
\end{gathered}
$$

As a result, the structure shown in Fig. 7, b) substitutes by the structure depicted in Fig. S1, c where the Y-like sub-system (contour VI) may be selected. Equivalenting this contour again by one sewer section with the parameter

$$
\begin{gathered}
\gamma_{V I}= \\
=\frac{\left(\gamma_{1}+\gamma_{11}\right) q_{1}+\left(\gamma_{I V}+\gamma_{11}\right)\left(q_{2}+q_{3}+q_{4}\right)}{q_{1}+q_{2}+q_{3}+q_{4}}= \\
=16,78 \cdot 10^{-3}
\end{gathered}
$$

we are going to the Fig. S1, $d$.

But the structure shown in Fig. S1, d) is the Y-like fragment (contour VII) in itself that may be substituted by one sewer (see Fig. S1,e). Thus, finally 


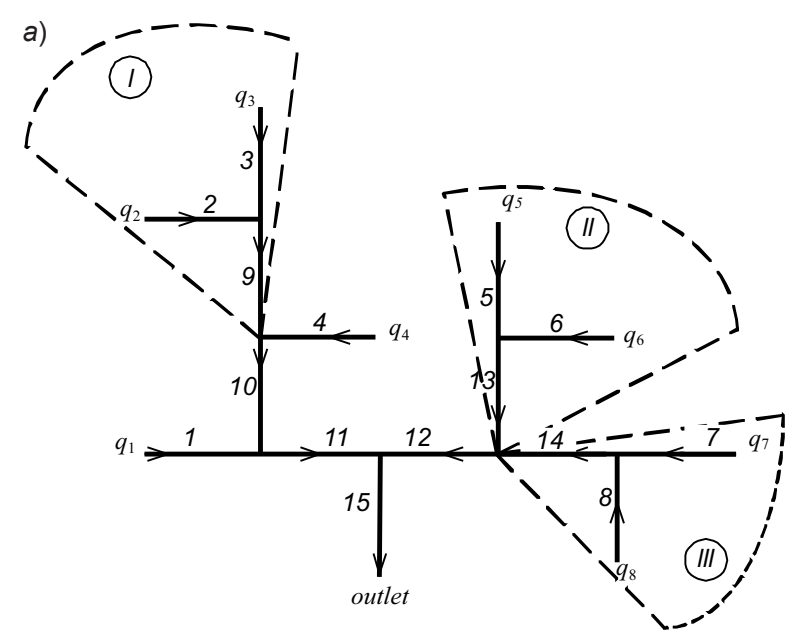

b)

c)

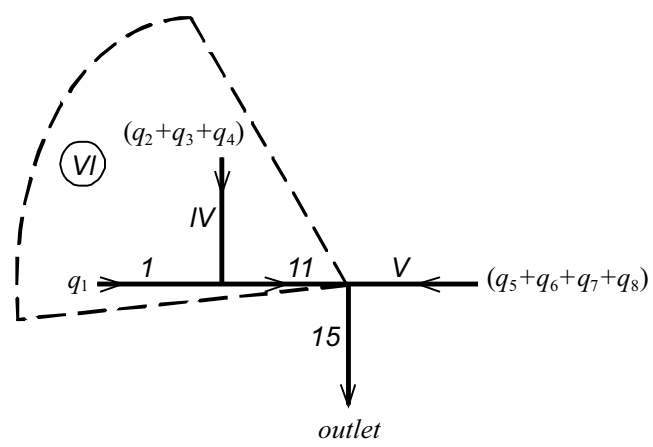

d)

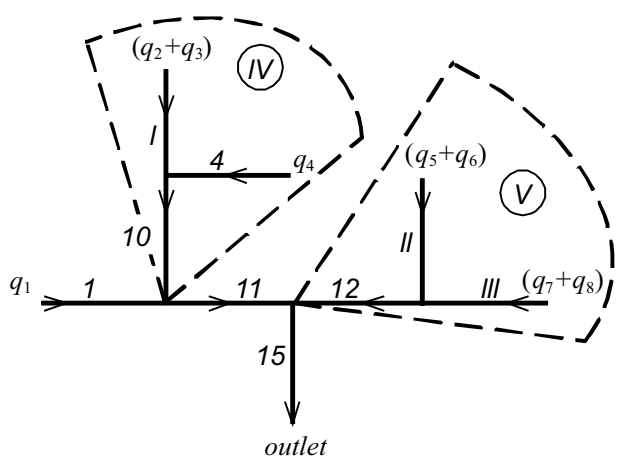

Fig. S1. Initial sewer network (a) and its sequential transformations $(b, c, d, e)$

Input data for calculations

\begin{tabular}{|l|l|l|l|l|l|l|l|l|l|l|l|l|l|l|l|}
\hline Section, $i$ & 1 & 2 & 3 & 4 & 5 & 6 & 7 & 8 & 9 & 10 & 11 & 12 & 13 & 14 & 15 \\
\hline Failure rate $\lambda_{i},(1 / \mathrm{yr})$ & 0,52 & 0,68 & 0,79 & 0,91 & 1,34 & 0,83 & 0,75 & 0,03 & 0,85 & 0,62 & 0,84 & 1,10 & 0,03 & 0,50 & 0,05 \\
\hline Repair rate $\mu_{i},(1 / \mathrm{yr})$ & 220 & 220 & 220 & 220 & 220 & 220 & 220 & 220 & 200 & 150 & 120 & 120 & 200 & 200 & 90 \\
\hline Parameter $\gamma_{i}=\lambda_{i} / \mu_{i}\left(\times 10^{3}\right)$ & 2,36 & 3,09 & 3,59 & 4,14 & 6,09 & 3,77 & 3,41 & 0,14 & 4,25 & 4,13 & 7,00 & 9,17 & 0,15 & 2,50 & 0,56 \\
\hline
\end{tabular}

\section{Network inlets sewage flow rates}

\begin{tabular}{|l|l|l|l|l|l|l|l|l|}
\hline Inlet, $i$ & 1 & 2 & 3 & 4 & 5 & 6 & 7 & 8 \\
\hline $\begin{array}{l}\text { Sewage flow rate } q_{i}\left(\times 10^{2}\right), \\
\left(\mathrm{m}^{3} / \mathrm{s}\right)\end{array}$ & 3 & 9 & 6 & 4 & 5 & 1 & 5 & 7 \\
\hline
\end{tabular}

we have the parameter $\gamma_{V I I}$ of one equivalent sewer substituting the initial network depicted in Fig. S1, a):

$$
\begin{gathered}
\left(\gamma_{V I}+\gamma_{15}\right)\left(q_{1}+q_{2}+q_{3}+q_{4}\right)+ \\
\gamma_{V I I}=\frac{+\left(\gamma_{V}+\gamma_{15}\right)\left(q_{5}+q_{6}+q_{7}+q_{8}\right)}{q_{1}+q_{2}+q_{3}+q_{4}+q_{5}+q_{6}+q_{7}+q_{8}}=16,00 \cdot 10^{-3} .
\end{gathered}
$$

The sequence of "decomposition-equivalenting" operations is completed. Hence, in this case, $\gamma_{e}=\gamma_{V I I}=0,016$. This means that, on the average,
$1,6 \%$ of the total sewage volume that entered the network inlets during time $T$, discharges from the sewer network to the environment arising from the network component failures. The accuracy of this measure increases as $T$ increases, that is characteristic for probabilistic problems at all.

Problem 2. Let us assume that specialists analyzing the results obtained in preceding Problem 1 come to the conclusion that the raw sewage discharge from the sewer network (Fig. S1,a)) is much too large, and, consequently, the network reliability needs to be increased. The question concerning replacement of some components by a new sewer pipe is discussed, but it is possible to replace only one sewer because available funds are limited. On the present evidence, 
it may be argued that the failure rate for a new sewer (manufacturer's data) is $\lambda_{n}=0,021 / \mathrm{yr}$; the repair rate $\mu_{n}$ is taken to be equal to 200 . It is desired to identify the preferential alternative.

First of all, we compute $\lambda_{n}=\lambda_{n} / \mu_{n}=0,1 \cdot 10^{-3}$. As before, we will take the discharged sewage volume as an efficiency index of the alternative to be accepted. Calculate this quantity assuming that the replacement of sewer section 1 in the initial network (Fig. S1,a)) has just been made. For this purpose, we substitute the input data (associated with the sewer 1) of the Problem 1, for one another (corresponding to the new sewer), namely $\gamma_{n}=0,1 \cdot 10^{-3}$. Carrying out the relevant calculations, we obtain the discharged sewage volume expressed as a percentage of the total sewage entered the network: 1,582\%. By repeating the similar calculations with respect to each network section we come to the results represented in Table 3.

Referring to Table 3, it is seen that the smallest volume of sewage to be discharged from the network occurs when the network's section 12 is replaced (in Table 3 this is highlighted in bold print). It is obvious that, under otherwise equal conditions, this alternative is preferable from the viewpoint of the reliability index accepted in this work.

The problems considered are simple as well; for this reason, the results seem to be trivial. Note, however, that the simplicity of the examples makes it possible to see the potential of the proposed method for practical use.

\section{Result of calculations}

Table 3

\begin{tabular}{|l|c|c|c|c|c|c|c|c|c|c|c|c|c|c|c|}
\hline Section to be replaced & 1 & 2 & 3 & 4 & 5 & 6 & 7 & 8 & 9 & 10 & 11 & $\mathbf{1 2}$ & 13 & 14 & 15 \\
\hline $\begin{array}{l}\text { Relative sewage volume } \\
\text { discharged from network, } \\
\%\end{array}$ & 1,582 & 1,532 & 1,547 & 1,559 & 1,524 & 1,590 & 1,558 & 1,599 & 1,444 & 1,408 & 1,220 & $\mathbf{1 , 1 9 1}$ & 1,599 & 1,527 & 1,553 \\
\hline
\end{tabular}

